\title{
Leituras por alunos do ensino médio de textos de cientistas sobre o início da física quântica
}

\author{
Readings by high school students about the beginning \\ of quantum physics through scientists' texts
}

\author{
Cassiano Rezende Pagliarini ${ }^{1}$ • Maria José P. M. de Almeida ${ }^{1}$
}

\begin{abstract}
Resumo: O objetivo deste estudo é compreender as interpretações de estudantes do ensino médio sobre as atividades de leitura por eles realizadas em uma aula de física num projeto de extensão de uma universidade estadual paulista, e sobre noções do início da Física Quântica, ao lerem textos escritos por cientistas. Utilizamos a Análise de Discurso, numa de suas vertentes francesas, para analisar as respostas dadas a um questionário aberto, com cinco perguntas, aplicado durante a aula. Constatamos que, provavelmente pelo fato de a leitura de textos de divulgação científica e de originais de cientistas não ser uma prática comum nas atividades escolares, a diversidade de sentidos produzidos pelos estudantes ao novo assunto, ao mesmo tempo que abre possibilidades para uma maior interação do professor, atenta para a necessidade de sua mediação quanto a dúvidas e equívocos.
\end{abstract}

Palavras-chave: Ensino de física. Física moderna e contemporânea. Ensino médio. Leitura. Divulgação científica. Análise do discurso.

\begin{abstract}
The aim of this study is to understand the interpretations of high school students about notions of the beginning of Quantum Physics, after reading scientists' texts, and also their interpretations about the reading activities, that took place in a physics class during an extension project of a public university in the state of São Paulo. We use Discourse Analysis, initiated in France by Michel Pêcheux, to analyze the student's answers to a questionnaire with five discursive questions. We realize that, probably because the reading of scientific dissemination texts and also scientists' original texts is not a common activity at the high school, the diversity of meanings given by the students to the new subject, allows a greater interaction but also alerts us to the necessity of the teacher's mediation about doubts and misconceptions.
\end{abstract}

Keywords: Physics teaching. Modern and contemporary physics. High school. Reading. Scientific dissemination. Discourse analysis.

\footnotetext{
${ }^{1}$ Universidade Estadual de Campinas (Unicamp), Faculdade de Educação, Programa de Pós-Graduação Multiunidades em Ensino de Ciências e Matemática (PECIM), Campinas, SP, Brasil.

E-mail: <pagliarini@gmail.com>
} 


\section{Introdução}

Pesquisas na área de ensino de ciências têm enfatizado a importância de uma formação científica ampla e geral, que seja significativa para os estudantes em todos os seus níveis de ensino. Mesmo para aqueles que não vão utilizar diretamente conhecimentos científicos em sua vida profissional, sua presença no ensino de nível médio se faz enriquecedora e necessária (NARDI, 1998; PIETROCOLA, 2001; SILVA, 2006). Na área de pesquisa em ensino de física, especificamente, é corrente a discussão sobre como tratar a inserção de tópicos de Física Moderna e Contemporânea (FMC) no Ensino Médio, bem como quais seriam os seus temas relevantes nesse nível de ensino (LOBATO; GRECA, 2005; OSTERMANN; MOREIRA, 2001; PINTO; ZANETIC, 1999; TERRAZZAN, 1992).

Segundo Terrazzan (1992), no início das discussões sobre esse tema de pesquisa, a necessidade de um debate que estabelecesse as formas de abordar os temas de FMC justificase na crescente influência que tais conteúdos exigem para o entendimento do mundo criado pelo homem atual, baseado fortemente em máquinas, aparelhos e artefatos tecnológicos que, cada vez mais, somente são compreendidos se algumas noções estabelecidas desde o final do século XIX forem utilizadas. Algumas pesquisas de revisão da literatura da área sobre a FMC no Ensino Médio auxiliam a destacar alguns pontos. No início da última década, Ostermann e Moreira (2000) atentaram para uma maior concentração de estudos relativos à apresentação de um tema específico de FMC em nível médio. Tratando em particular do ensino de Física Quântica (FQ) introdutória agora nos níveis médio e universitário, que inclui a formação de professores, Greca e Moreira (2001) apontam para uma classificação de três grandes grupos dos artigos de pesquisa sobre o tema, a saber: concepções dos estudantes, críticas à abordagem tradicional e propostas de inovações didáticas.

Em outras revisões bibliográficas mais recentes, segundo Pereira e Ostermann (2009) e Silva e Almeida (2011), essa última voltada especificamente para a FQ no Ensino Médio (EM), é possível verificar um aumento na produção de pesquisas sobre FMC com propostas de atividades sobre sua inserção nesse nível de ensino. Alguns exemplos, sobretudo aqueles que envolvem a aplicação de atividades voltadas ao ensino da teoria da relatividade, indicam possibilidades concretas de abordagens histórico-filosóficas da ciência, não apenas a tradicionalmente técnica excessivamente matemática, destacando diversas relações entre a física e outras produções culturais da humanidade (GUERRA; BRAGA; REIS, 2007; KARAM; CRUZ; COIMBRA, 2007; WOLFF; MORS, 2006). Nessa perspectiva, ao considerar os aspectos filosóficos e epistemológicos da FMC, Brockington e Pietrocola (2005) atentam para a necessidade de discussões acerca da ontologia, a natureza última por trás dos objetos quânticos. Assim, o ensino de física moderna deve contemplar discussões que também apontem para o fato de os modelos não serem cópias da realidade, estabelecendo uma nova relação com o conhecimento.

\section{Justificativa, objetivo e questões do estudo}

A ciência e a tecnologia vêm provocando, ao longo de seus desenvolvimentos, mudanças no ambiente como um todo e nos modos de vida da população mundial. Esses avanços tomam rumos nos quais cada vez mais novos desafios se colocam para as pessoas nas mais diversas 
situações do dia a dia. Trazer à tona a questão de que a ciência, juntamente com a tecnologia, faz parte do cotidiano das pessoas significa reconhecer que os desenvolvimentos científicos e tecnológicos se integram a vários outros aspectos como o social, o político, o cultural e o pessoal. Assim, considerando que, nos dias de hoje, os seres humanos, além de conviverem com fenômenos naturais, apoiam, de diferentes maneiras, suas atividades em desenvolvimentos tecnológicos, cada um acaba por possuir suas próprias representações e concepções do mundo que o cerca.

Apesar do convívio em situações tão diversificadas, cabe reiterar que, enquanto o ensino na sala de aula ainda se configura, para a maioria da população, como o principal meio de acesso a aspectos da ciência que possam contribuir para a formação dos estudantes de maneira cidadã, os outros meios (museus e centros de ciência, documentários educativos, divulgação jornalística pelas diversas mídias, etc.) têm o importante papel de complementar essa formação (MARANDINO, 2003). Assim, deve-se procurar uma formação científica que seja mais ampla e geral, uma vez que, formalmente, na grande maioria das situações, será essa a formação que muitos, que não terão profissões ligadas ao meio científico, levarão para a vida toda. E se pensarmos na física, uma vez que neste estudo trabalhamos com um tema incluído entre os conhecimentos nela produzidos, consideramos que:

Ao mesmo tempo, a física deve vir a ser reconhecida como um processo cuja construção ocorreu ao longo da história da humanidade, impregnado de contribuições culturais, econômicas e sociais que vêm resultando no desenvolvimento de diferentes tecnologias e, por sua vez, por elas sendo impulsionada. (BRASIL, 1999, p. 59).

Ao pensarmos alguns conhecimentos da física como básicos para compreensão, ação e satisfação cultural do cidadão de hoje, atentamos para o fato de que em seu ensino de nível médio os currículos "[...] tradicionalmente têm seguido uma estrutura conceitual linear e hierárquica, sem transpor as fronteiras das teorias clássicas produzidas até o século XIX” (SÃO PAULO, 2012, p. 96). Apesar de já podermos contar com algumas propostas resultantes de pesquisas e até mesmo com algumas experiências escolares diferenciadas desse esquema, elas ainda são pontuais.

O ensino de física que se apresenta atualmente na maioria dos ambientes escolares de nível médio mostra-se carente se analisarmos não só seus métodos, práticas e abordagens, mas também seus próprios conteúdos. Quando encaramos a ciência física como um tipo de conhecimento que faz parte da cultura da humanidade (PINTO; ZANETIC, 1999), vemos que ele não coloca em pauta os resultados obtidos mais recentemente e, principalmente, os processos de produção, as novas concepções de mundo e maneiras de se pensar e interpretar os fenômenos naturais, presentes desde o início do século XX, bem como sua relação com as diversas tecnologias, que cercam nosso cotidiano.

Como destacam Lobato e Greca (2005), é de grande importância a investigação acerca do ensino de FMC no EM, sendo particularmente a FQ de extrema relevância, num sentido em que coloca seus paradigmas como uma nova forma para o pensar e o fazer ciência.

No que se refere especificamente a esse ramo da física, Silva e Almeida (2011) revisaram 16 publicações que apresentam a elaboração e/ou a aplicação de propostas de ensino de FQ. 
Mesmo constatando que mais de metade dessas propostas tinham sido testadas, os autores, em suas considerações finais, julgam esse número muito pequeno dada a grande variedade de assuntos relacionados à FQ e concluem pela necessidade de mais pesquisas em sala de aula.

Ainda nesse sentido, como destacado por Almeida (2004), a convivência com diferentes vertentes numa mesma disciplina abre a possibilidade para que se evite um único modelo, tido como ideal, de racionalidade científica. Assim, se faz necessário

[...] o estudo de produções científicas que não se prendam apenas ao que foi feito há muito tempo, como, no caso da física, uma abordagem de teorias do século XX e mesmo de alguns dos conteúdos da ciência que hoje está sendo produzida, ultrapassando os limites da física clássica nos diferentes níveis de ensino. (ALMEIDA, 2004, p. 24).

Entretanto, é fato que, para pensar o ensino de qualquer conteúdo, não basta pensar o que ensinar, mas também de que maneira fazê-lo. Forma e conteúdo não são dissociáveis em situações de ensino. Sabemos que a produção da FMC é feita numa linguagem matemática de difícil acesso, a não ser para aqueles que a produzem. Assim, pesquisas exploratórias que mostrem como foram trabalhados conteúdos de FQ com alunos de EM, em determinadas situações, podem contribuir significativamente para que cada vez mais, também em outras situações nesse nível, esses conteúdos sejam incorporados aos currículos oficiais e ao ensino efetivo.

O estudo aqui apresentado foi pensado com base numa aula ministrada num curso de extensão destinado a alunos do EM. O conteúdo refere-se ao início da FQ, e a organização da aula apoiou-se em textos de cientistas, sendo sua abordagem pautada em atividades de leitura e escrita, além da mediação com interlocuções do professor.

Nosso intuito com a realização do estudo foi compreender as interpretações dos estudantes, que participaram daquela aula, sobre o conteúdo propriamente dito e sobre a atividade de leitura, ao lerem os textos e dialogarem com o professor e/ou entre eles.

Nesse sentido, iniciamos a pesquisa com as seguintes questões de estudo, formuladas em relação ao grupo de estudantes aqui considerado:

1) Como os estudantes do EM produziram sentidos na leitura de textos de cientistas sobre o início da FQ? de física?

2) Como os estudantes do EM se posicionaram em relação à leitura de textos em aulas

\section{Apoio teórico-metodológico}

Neste estudo, utilizamos como apoio teórico-metodológico algumas noções da Análise de Discurso (AD), na vertente iniciada por Michel Pêcheux. A AD considera a linguagem numa perspectiva em que é tomada como sendo não transparente e não somente suporte para o pensamento, mas, sim “[...] como mediação necessária entre o homem e a realidade natural e social. Essa mediação, que é o discurso, torna possível tanto a permanência e a continuidade quanto o deslocamento e a transformação do homem e da realidade em que ele vive". (ORLANDI, 2012a, p. 15). 
Nessa perspectiva teórica, sendo o discurso entendido como efeito de sentidos entre locutores, procura-se a compreensão de como determinado discurso foi formulado. Nesse processo, além de consideradas as condições imediatas e as situações próprias da tomada do discurso, questões que remetem à exterioridade desses dizeres são de grande relevância. Assim, é a partir dessa noção de discurso que, ao perguntarmos como tal fala/escrita ou imagem foi formulada, estamos nos remetendo ao modo como esses processos discursivos produzem significados, ou seja, as condições de produção desses dizeres subentendem também as condições materiais sócio-históricas em que "[...] a história tem seu real afetado pelo simbólico". (ORLANDI, 2012a, p. 19).

A produção de sentidos supõe também uma repetição em seu dizer, uma vez que ele se inscreve em um já-dito anterior que torna seu enunciado interpretável. Orlandi (2012b, p. 70, grifos do autor) distingue três modos diferentes em que ocorre a repetição, a saber:

a) a repetição empírica, exercício mnemônico que não historiciza;

b) a repetição formal, técnica de produzir frases, exercício gramatical que também não historiciza;

c) a repetição histórica, a que inscreve o dizer no repetível enquanto memória constitutiva, saber discursivo, em uma palavra: interdiscurso. Este, a memória (rede de filiações), que faz a língua significar. É assim que sentido, memória e história se intrincam na noção de interdiscurso.

Desse modo, é no próprio reconhecimento da existência de movimentos entre esses diferentes modos de repetição, a partir da "cópia" e passando por outra de reformulação no nível da organização gramatical, o "dizer com suas palavras”, até a inscrição de sua memória constitutiva numa formulação que produz um novo dizer no meio de outros, que reside a possibilidade mesma de se constituir uma aprendizagem. Cabe então à escola sustentar uma mediação que possibilite se relacionar com o repetível, ou seja, “[...] criar condições para que o aluno trabalhe sua relação com suas filiações de sentido, com a memória do dizer”. (ORLANDI, 1998, p. 14).

Pensando algumas das condições para que a mediação se efetive, entendemos como pertinente voltar nossos olhares para as maneiras como o discurso científico é trabalhado na escola, mais especificamente, em nosso caso, o relativo à física. Levamos então em consideração o discurso escolar da física, constituído no entrecruzamento do discurso da física com outros discursos. Para Almeida (2004, p. 58), “[...] a compreensão do discurso científico não é condição suficiente para se compreender o discurso escolar relativo à ciência". A autora ainda considera que, uma vez que o conhecimento construído no âmbito escolar, sujeito a relações de medição didática, não coincide com o processo de construção do conhecimento científico, não existe também possibilidade de que coincidam os discursos científico e escolar, mesmo nos casos em que este se se refira àquele. (ALMEIDA, 2004, p. 60).

Quando esse fato não é levado em conta, e nos parece ser o caso da grande maioria das vezes quando se trabalha conhecimentos da física na escola, acaba por ser determinante, na instituição, o funcionamento do discurso pedagógico autoritário. Ou seja, o discurso pedagógico (DP), segundo Orlandi (1996, p. 28), "[...] um dizer institucionalizado que se garante garantindo a instituição em que se origina e para a qual tende: a escola", caracteriza-se em sua definição própria como um discurso neutro transmissor de informações, de forma que, do ponto de vista da ciência, seu referente primeiro tem função puramente cognitiva e informacional. Porém, pensando a prática e questionando essa neutralidade suposta, a autora busca outra tipologia dados os funcionamentos distintos que estabelece a partir do critério da relação entre os interlocutores 
e aquilo de que falam, o referente. É aí que se dá seu funcionamento autoritário, na medida em que se apresenta sem nenhuma neutralidade, baseado numa contenção do caráter polissêmico da linguagem, ou seja, do diferente, da tensão que aponta para um rompimento e da procura de reversibilidade na relação, estabelecida entre os interlocutores (professor/aluno). Assim, para a autora, no discurso autoritário, “[...] o agente do discurso se pretende único e oculta o referente pelo dizer". No DP, esse é dissimulado como transmissor de informação, caracterizando-a “[...] sob a rubrica da cientificidade". (ORLANDI, 1996, p. 29).

No DP polêmico há o controle da polissemia, sendo que os interlocutores buscam, cada um por si, direcionar o referente do discurso. E segundo a autora:

[...] o DP, sendo um discurso institucional, reflete relações institucionais das quais faz parte; se essas relações são autoritárias, ele será autoritário. O seu mal de raiz é, pois, refletir a ordem social na qual existe. Mas como esta não é uma relação mecânica, alguma coisa escapa e é sempre possível a crítica. [...] Nossa realidade é a presente e a minha proposta atual é a de buscarmos, professores e alunos, um DP que seja pelo menos polêmico e que não nos obrigue a nos despirmos de tudo que é vida lá fora ao atravessarmos a soleira da porta da escola. (ORLANDI, 1996, p. 37).

Essa recomendação foi levada em conta na organização da aula analisada neste estudo.

\section{Condições de produção das informações coletadas na aula}

As informações que viabilizaram os dados analisados neste estudo foram coletadas na última aula de um projeto extensão, o Programa de Formação Complementar para Alunos do Ensino Médio (PROFEM), vinculado ao Programa Novos Talentos da Coordenação de Aperfeiçoamento de Pessoal de Nível Superior (CAPES), no qual estudantes dos segundos e terceiros anos do EM de duas escolas públicas da cidade de Campinas, SP, frequentaram a Universidade ao longo de pouco mais de um ano, duas tardes por semana. Nesse ano, as aulas foram sobre diversas temáticas, pensadas com o intuito de possibilitar uma complementação para a formação escolar desses estudantes.

O projeto contou com a participação total de 25 estudantes interessados nas atividades quando da divulgação em suas escolas. Eles recebiam transporte fretado para locomoção até a universidade e lanche, além de ter a frequência no curso controlada para o recebimento de certificado de participação (mínimo exigido de $75 \%$ de presença). As aulas foram ministradas por professores da Universidade, e estudantes de pós-graduação e de licenciatura. Para o desenvolvimento das aulas foram incentivadas pelo coordenador do PROFEM: a realização de atividades em espaços diversificados, como laboratórios, museu de ciências e demais espaços educativos; e a aplicação de atividades pautadas em pesquisas que estavam em desenvolvimento. Elas incluíam sequências didáticas, unidades de ensino, novas metodologias, uso de tecnologias, atividades em laboratório, textos para leitura.

A proposta da aula, que viabilizou este estudo, foi organizada para esses estudantes com o título Virando a física de cabeça para baixo!, o qual apareceu na primeira imagem apresentada 
aos estudantes, na tela de projeções, no início da aula. A aula de aproximadamente três horas incluiu o desenvolvimento de atividades de leitura de um texto de divulgação e um texto original, ambos escritos por cientistas. Com esses textos visávamos trabalhar conteúdos relacionados a noções básicas e fundamentais da FQ elaborados no início do século XX. Esses conteúdos, em muitos casos, se colocaram em confronto com conceitos bem consolidados da física clássica. Além de tratar de conteúdos de FMC que usualmente não estão presentes no ensino escolar da física, a proposta também se justifica por buscar desmitificar a visão comum de que a prática escolar adequada em aulas, envolvendo o ensino de física, é a apresentação de definições e leis e a realização de exercícios repetitivos com aplicações numéricas de tais definições ou leis.

A aula ministrada pelo primeiro autor deste estudo foi estruturada em três partes. Inicialmente foi realizada uma aproximação com a turma, quando uma introdução ao tema/título foi feita por intermédio de um questionamento geral sobre o que, em suas visões, poderia tratar a aula que se propunha a "virar a física de cabeça para baixo", seguida então da apresentação dos assuntos específicos a serem debatidos e expostos sobre a FQ. Também foi explicada a forma como as atividades seriam realizadas, com leituras de textos de cientistas.

A primeira parte da aula propriamente dita consistiu na apresentação aos alunos de um pequeno trecho introdutório do texto de divulgação científica "Física Quântica: o estranho comportamento do mundo microscópico" (FERREIRA, 2003) para leitura inicial e primeiro contato com o tema proposto. Os primeiros parágrafos do texto, utilizado para a leitura, tratam de destacar inicialmente que diversos avanços tecnológicos foram decorrentes do desenvolvimento da FQ no início do século XX. O autor também menciona que a FQ transformou as concepções do homem acerca do universo, permitindo desvendar mistérios sobre a estrutura da matéria. Ao fazer um contraponto com os fenômenos do cotidiano, o texto destaca ainda que, apesar de eles estarem presentes no mundo quântico e serem inimagináveis para o nosso dia a dia, ele seria impensável sem o comportamento bizarro de átomos, moléculas e partículas de luz (FERREIRA, 2003, p. 153).

Num segundo momento, o trecho de abertura do capítulo salienta que, para uma compreensão dos princípios da FQ, é preciso constatar que as leis que governam fenômenos físicos dependem da escala dos objetos envolvidos, ou seja, que o mundo microscópico se comporta diferentemente dos objetos da vida cotidiana. Passando por uma exemplificação das partículas constituintes do átomo e das proporções envolvidas, o autor destaca alguns problemas do modelo atômico que assume órbitas para os elétrons em torno do núcleo. Em analogia com o movimento dos planetas em torno do Sol, cita o colapso que sofreriam átomos justapostos para concluir que há algo no movimento dos elétrons o que o faz diferir do movimento planetário. Citando Max Planck, como o cientista responsável pelas primeiras ideias que visaram explicar a coerência no comportamento dos átomos, traz um quadro intitulado "Constante Fundamental da Natureza" para explicar algumas noções de como a constante de Planck surgiu de seu trabalho investigativo acerca das interações entre radiação e matéria no problema da radiação de um corpo negro. A parte do texto, que finaliza o trecho selecionado para a leitura inicial dos estudantes, apresenta alguns conceitos físicos como: radiação eletromagnética, frequência, intensidade, temperatura, espectro eletromagnético visível, energia do campo eletromagnético e pacotes de energia. É uma parte que se mostra mais densa em conteúdos, uma vez que busca delimitar qual era o problema de investigação de Planck e as ideias incompatíveis da física clássica com o que se observa no fenômeno da radiação do corpo negro, para então colocar a 
constante $h=6,6261 \times 10^{-34}$ como uma escala absoluta para quando um fenômeno deve levar em conta os aspectos ditos quânticos.

A proposta de como seria feita a leitura dos trechos iniciais do texto foi aberta aos estudantes, sendo que eles preferiram realizar uma leitura individual. Juntamente com a distribuição dos textos, foi também disponibilizado a cada um deles um questionário contendo cinco questões abertas, relacionadas às atividades a serem desenvolvidas ao longo da aula. Foi informado que o questionário não tinha seu preenchimento obrigatório e tampouco visava a avaliação dos estudantes quanto à interpretação dos assuntos tratados. Era, sim, uma forma de retorno com a qual o professor/pesquisador poderia verificar as impressões e as opiniões dos estudantes sobre a dinâmica proposta, podendo, inclusive, auxiliar a maneira como as atividades seriam levadas para aplicação nas escolas. Ao todo, dentre os 17 presentes na aula, 12 estudantes responderam integralmente o questionário, três parcialmente e dois não o retornaram ao professor/pesquisador no final da aula. Após a leitura inicial realizada pelos estudantes, seguida de um tempo para a resposta à primeira questão, foi aberto pelo professor/pesquisador um breve debate sobre as impressões, os pontos considerados relevantes, as principais ideias e dúvidas específicas que gostariam de destacar sobre esse primeiro texto.

Após o tempo de discussão sobre a leitura inicial, a segunda parte da aula consistiu numa apresentação expositiva do professor/pesquisador, com auxílio de projeção de slides para visualização de imagens, gráficos e pequenas simulações de modelos físicos retirados de um website para simulações em ciências $^{2}$. O objetivo principal era realizar uma mediação das noções e das ideias sobre FQ presentes no primeiro texto e também contextualizar o assunto a que se referia o trecho do segundo texto a ser lido em seguida pelos estudantes na terceira parte da aula. Para essa exposição do professor/pesquisador, foi adotada como estratégia uma abordagem histórica com auxílio de imagens, para o caso da apresentação do chamado espectro eletromagnético; e de pequenas simulações, como mencionado, para apresentação dos modelos atômicos, uma vez que referências ao átomo eram feitas em ambos os textos das atividades de leitura. O exemplo histórico abordado para evidenciar o caráter diferenciado do comportamento físico dos fenômenos do mundo microscópico foi o da natureza da luz, sendo a primeira noção básica destacada da FQ a do comportamento dual, ora corpuscular ora ondulatório, dependendo do tipo de interação do sistema de medidas, para a luz. A explicação foi precedida, também com abordagem histórica, de uma discussão sobre a descoberta do elétron e as concepções sobre o comportamento e a natureza dos átomos. Em seguida, discutiu-se sobre o átomo e as diferentes elaborações de modelos para explicar seu comportamento até o entendimento diferenciado que se obteve para os fenômenos ditos quânticos. Nesse ponto, a segunda noção quântica discutida especificamente com os estudantes foi a de quantização da energia nos chamados quanta, pacotes de energia que só poderiam assumir certos valores e não qualquer um nesses diversos tipos de fenômenos microscópicos. Após a exposição de uma simulação de modelos atômicos, que iam da visão de um comportamento de acordo com a física clássica até elaborações posteriores que destacavam seu comportamento quântico na interação com fótons de luz, passou-se ao intervalo para o lanche dos estudantes.

\footnotetext{
${ }^{2}$ Disponível em: <https://phet.colorado.edu/>. Acesso em: 15 fev. 2016.
} 
A parte final da aula, que como já dissemos foi no total de aproximadamente três horas, consistiu na leitura de um trecho de quatro páginas do texto "Novas vias de acesso ao conhecimento na física", de autoria do cientista Max Planck, produzido para uma conferência, em 1913, na Universidade de Berlim, no qual o cientista aborda a necessidade de revisão do postulado clássico no que se refere ao caráter contínuo das ações dinâmicas (PLANCK, 2012). Nesse trecho, analogias são usadas para comparar como se dá continuamente o fracionamento de energia em situações cotidianas, em que átomos interagem com a luz, introduzindo a noção de quantum para um fracionamento finito nas trocas de energia. A partir do exemplo de ondas numa superfície da água, Planck argumenta em favor de uma similaridade com o caso do calor radiante e da luz:

[...] Também aí haverá causas que deterão o fracionamento da energia, que não poderá ir além de certo quantum de valor finito. Essas causas frearão ainda mais o fracionamento se as ondas forem mais curtas, isto é, se as vibrações forem mais rápidas.

Como tais quanta, de natureza puramente dinâmica, se estabelecem? Ainda não se pode afirmar nada a esse respeito. Em todo caso, a hipótese dos quanta leva a admitir que há fenômenos que não ocorrem de maneira contínua, mas bruscamente e, por assim dizer, explosivamente. (PLANCK, 2012, p. 95).

Após a leitura, novamente individual, alguns estudantes já se preocuparam em responder às demais perguntas do questionário e, após aguardar que todos concluíssem a leitura, novamente o professor/pesquisador abriu espaço para os estudantes discutirem pontos sobre a leitura que gostariam de levantar, tais como dificuldades no entendimento de ideias e/ou termos específicos da física, pontos interessantes sobre os exemplos ou dúvidas sobre as referências que o cientista faz sobre questões ligadas ao funcionamento da ciência.

A discussão final foi mais breve que as demais atividades que a aula englobou, principalmente devido ao fato de se tratar da última aula do projeto. Em razão desse fato, foi reservado um espaço de cerca de 20 minutos para que o coordenador do projeto pudesse entregar os certificados, realizar uma fala de encerramento e agradecê-los pela presença no projeto. Em seguida, houve uma pequena confraternização com café disponível para os presentes. Aqui nos propusemos a considerar apenas as produções escritas dos questionários dos estudantes.

\section{Análise das respostas ao questionário}

Buscando responder as questões formuladas para este estudo, neste item analisamos as respostas escritas, fornecidas pelos estudantes que participaram da aula, para o seguinte questionário:

Sobre o texto introdutório "Física Quântica: o estranho comportamento do mundo microscópico"

1. Se após esta aula você tivesse que contar a um amigo do que trata o texto que acabou de ler, o que você contaria? 


\section{Sobre as discussões e a leitura do $2^{\circ}$ texto: "Novas vias de acesso ao conhecimento na física"}

1. Você achou alguma das ideias sobre física quântica que lemos ou debatemos interessante? Gostaria de conhecer mais sobre este assunto?

2. Que dificuldades você teve na leitura deste segundo texto?

Mesmo que três estudantes tenham entregado o questionário sem preencher seus nomes, atribuímos a todos os 15 respondentes nomes fictícios para nos referirmos a seguir às suas respostas. Foi mantida a ortografia original dos estudantes, notando que, mesmo em se tratando de alunos do segundo e do terceiro ano do EM, vários equívocos ortográficos ocorreram em suas respostas. Entretanto, é necessário levar em conta a situação em que eles escreveram, considerando seu tempo limitado e a provável falta de revisão do que foi escrito.

Iniciamos a análise pelas duas últimas questões, as que pediam opinião sobre os tipos de atividades desenvolvidas na aula. Essas respostas fornecem indícios sobre o envolvimento dos estudantes com o trabalho realizado, como mostramos a seguir. Mas também apontam alguns imaginários sobre essa e outras aulas e sobre escola.

Nas condições de produção que funcionaram na aula, objeto deste estudo, as manifestações dos estudantes, sobre terem gostado da leitura de textos e das discussões numa aula de física, foram bastante positivas. Dentre elas, reproduzimos aqui as seguintes produções de sentidos em respostas à quarta questão.

\section{Ester - É uma formula nova de ensinar e aprender fisicia, através da leitura e da discussão com todos os alunos, parece que fica bem mais dinâmico e mais facil de analisar o conteudo; Jéssica - Achei interessante, a aula ficou dinâmica e utilizamos outros métodos de aprendizado. \\ Thiago - Bem, um leitou mais ou menos facio de indeter.}

Também pudemos notar que algumas respostas evidenciam que os estudantes responderam essa questão não levando em conta apenas as condições de produção imediatas, ou seja, a aula de que estavam participando. Eles utilizaram suas memórias discursivas para fazer comparações com aula convencional/aula, escola, contas e fórmulas, como indicam as seguintes respostas:

\footnotetext{
Ana - Achei bem mais interessante que uma aula convencional.

Maria - Muito diferente do que estou acostumada, pois só havia tido aulas com contas e fórmulas, sem muito conteúdo ou informação. Essa aula foi clara e bem discutida, com muitas ideias e curiosidades interessantes.

Thamiris - Perfeito, pelas aulas de física na escola não ter essa dinâmica, muitos alunos disperçam pois só prende a atenção de quem realmente gosta de contas e fórmulas, mas para o resto, fugir desse sistema é muito bom para.
}

A estudante Ana não dá indícios do que considera uma aula convencional, enquanto Maria associa aulas (possivelmente as de física) com fórmulas e contas a pouco conteúdo, possivelmente relacionando conteúdo ao que estava contido nos textos lidos. Thamiris manifesta seu imaginário sobre o que ocorre com alunos que não gostam de contas e de fórmulas. Sua 
representação, provavelmente calcada no que observa nas aulas de física de que participa na escola, é que eles se dispersam.

Dessa forma, com os exemplos dos discursos aqui transcritos, notamos que, ao solicitar a opinião dos alunos numa questão aberta, além de opiniões/interesses sobre a atividade realizada, obtivemos com algumas respostas indícios do que os teria levado a elas e comparações com outras situações relacionadas ao ensino.

Para a quinta questão, possivelmente devido a ela ter duas partes distintas, alguns estudantes só responderam uma delas. Entretanto, seis, dos 12 que responderam todas as questões, o fizeram respondendo afirmativamente à primeira parte, ou seja, dizendo já ter lido algo escrito por um cientista. Mas precisamos ter em conta que não foi explicitado e, portanto, não temos suas representações sobre o que consideravam algo escrito por um cientista. Respostas como as de Ester e Maria, respectivamente, "Sim, ja havia lido outros assuntos" e "Sim, algo como pesquisas escolares", não nos esclarecem esse questionamento. O mesmo ocorre com a seguinte resposta negativa de João: "Nunca havia lido um livro escrito por um cientista". Mesmo a resposta de Nicole, embora mais explícita, ainda deixa dúvida se o texto que ela disse haver lido tinha sido escrito por um cientista: "Já, meu professor de física passou um livro sobre isso na aula de física quântica [separada da aula normal, fora da grade escolar]".

Essa resposta, no que se refere à atividade ter sido realizada fora da grade escolar, é mais uma evidência do quanto a FMC ainda não é considerada, no ensino médio, conteúdo próprio das aulas que ali ocorrem.

As respostas à segunda parte da quinta questão foram bastante esclarecedoras com respeito ao imaginário dos estudantes sobre a aula de que tinham acabado de participar, e também sobre a possível influência que ela pode ter tido sobre a predisposição desses estudantes para virem a ler outros textos, mesmo admitindo-se que não sejam explícitas suas representações sobre o que sejam textos escritos pelos próprios cientistas, apesar de terem nesse dia lido dois deles.

Priscila - Sim, porque seria muito mais entender com a explicação dos ciêntistas do que com as explicações dos professores.

Ester - Sim, pois parece uma forma pessoal do cientista, pois ele passou por toda a experiencia e foi todo pesquisado e elaborado para isso.

Ana - Sim, gostaria de ler outros escritos de Planck.

Maria - Sim, pois me fezpensar que é muito mais interessante ver vários lados de uma coisa só.

Jéssica - Sim, gostaria de ler outros textos escritos pelos próprios cientístas pois a esplicação é melhor, os experimentos são relatados com mais facilidade no meu ponto de vista. Marisa - sim porque seria muito mais fácil de se entender as coisas através das explicações dos próprios cientistas, porque muitas vezes os professores não conseguem ensinar corretamente.

Com relação a essas respostas, apesar de promissoras no sentido de esses estudantes possivelmente virem a efetuar outras leituras relacionadas a temas da ciência no futuro, não podemos descartar a possibilidade de eles apenas estarem comparando essa aula às usuais na escola, com a realização quase exclusiva de exercícios, nos quais talvez tenham mais dificuldade. A maior informalidade presente nessa aula talvez tenha tido um peso significativo. 
Mesmo assim, reproduzimos seis respostas dos estudantes que responderam todas as questões e positivamente à segunda parte da quinta questão, por julgarmos bastante relevante notar a variedade de justificativas que eles forneceram para gostar de ler outros textos que admitem como escritos por cientistas. Aparentemente, as memórias de Priscila, Jéssica e Marisa as levaram a fazer comparações nas quais privilegiaram a aula da qual tinham acabado de participar. Detendo-se na pergunta formulada, parece ainda terem generalizado o que ocorrera nessa aula para outras possíveis explicações de outros cientistas, chegando mesmo a estudante Marisa a julgar quem ensinaria certo - o cientista -, e quem, às vezes, não o faria corretamente.

É interessante também notar a produção de sentidos de Jéssica sobre o caráter facilitador do relato de experimentos, destacando o sentido positivo da leitura de textos de cientistas. Por outro lado, Ester destaca o caráter pessoal dos relatos lidos e, em seu imaginário, situa a vida do cientista como a geradora da facilidade encontrada, enquanto Ana evidencia sua preferência pelo texto lido, ao manifestar interesse pela leitura de outros textos de Planck. Já Maria se detém na própria natureza do texto lido ao valorizar a abordagem dos vários lados de uma coisa só, possivelmente influenciada de modo positivo pela presença de analogias e metáforas no texto de Planck, ainda que sem citar esse fato explicitamente.

As respostas para a segunda parte da questão cinco dos outros seis estudantes que responderam todas as questões completam a diversidade na produção de significados desse grupo, proporcionada pela aula, incluindo a formulação dessa questão aberta. Camila, inclusive, manifesta seu interesse por outros temas: "Gostaria de abordar outros temas interessantes que fogem da teoria e tenha mais praticidade". Nicole e Larissa não justificam suas respostas: "Sim, gostaria".

Entretanto, as respostas positivas à leitura não foram unânimes. Três estudantes responderam negativamente: João: "Não gostaria de ler livros parecidos, por que são assuntos complexos", Thiago: "Não" e Thamiris: "Não pelo fato de eu não ter muito interesse pelo assunto, mas é bastante interessante".

Passamos agora para a produção de sentidos explicitados nas respostas dos estudantes às primeiras questões. Ao buscarmos compreender a produção sobre a leitura de alguns parágrafos de Ferreira (2003), na primeira questão, pedindo-lhes que contassem a um amigo o que dizia o texto, notamos que 10 dos 12 que responderam todas as questões se referiram nessa resposta à "física quântica".

Uma das duas estudantes que não fizeram essa referência forneceu uma resposta bem genérica, na qual, aparentemente, manifesta seu imaginário sobre a ciência. Maria responde: "Que muitas coisas do nosso dia-a-dia tem a presença da ciência/ física e são praticamente ocultas para nós: tanto nosso passado como nosso futuro teve e terá sempre a presença da ciência para nos mostrar e provar coisas incriveis". Enquanto a resposta da outra estudante, Thamiris, que não se referiu explicitamente à física quântica, ficou mais próxima do tema do texto por se referir a partículas microscópicas: "Contaria que o texto fala sobre as partículas que compões a matéria. Tudo de grande que vemos no mundo é composto por milhares de particulas microscópicas unidas".

Por outro lado, ao lermos a seguinte resposta de Priscila, ao falar da FQ: "Que aprendi o que significa o que é física quântica", notamos o quanto ela é genérica. Entretanto, a mesma estudante, ao responder a segunda questão, sobre se havia achado alguma das ideias lidas ou debatidas interessante, e se gostaria de conhecer mais sobre o assunto, responde: "Acho que gostaria muito de estudar melhor sobre este assunto!!! E as físicas quânticas são muito interesantes e inperseptiveis no nosso dia-a-dia" e para a terceira questão aponta a: "dificuldade na escala de grandezas". Apesar de Priscila ter se referido à FQ no plural, tanto o vocábulo "imperceptíveis", quanto a referência 
à dificuldade com a escala de grandeza, são indícios do quanto ela conseguiu se aproximar da escala de grandeza que lhe causa dificuldade.

Em outros estudantes que se referiram à FQ em resposta à primeira questão, podemos notar movimentos de repetições formais, mesmo que em respostas sintéticas, nas quais, para essas sínteses, identificamos um início de reelaborar com suas palavras. A estudante Ana responde que "Contaria que, o texto abordava sobre física quântica e que explicava sobre o principio da física, sobre átomos e a teoria de Max Planck e de como os átomos são compostos", enquanto Thiago destaca que "O texto fala sobre física quântica e dos átomos estuda os comportamentos do mundo microscópico. A física quântica ajunda na saúde". As referências, na primeira resposta, a átomos e a Marx Planck; e na segunda, a mundo microscópico e a saúde, são noções presentes no primeiro texto lido, quando Ferreira (2003, p. 153-155) diz que "estamos cercados de aparatos eletrônicos, técnicas cirúrgicas [...] corpos microscópicos como átomos e moléculas [...]. As primeiras ideias para explicar de modo coerente o comportamento dos átomos surgiram com Max Planck [...]”.

É interessante também notarmos que a aula fez com que alguns alunos, já nessa primeira resposta, se manifestassem sobre a "facilidade" da FQ, provavelmente ao se lembrarem de algumas de suas dificuldades relacionadas a como eram usualmente as suas aulas. A resposta a seguir de uma das estudantes aponta para o fato de que a produção de sentidos por estudantes sobre um conteúdo científico, ao ser explorado pela e na escola, está associada à forma como é realizada a sua abordagem.

Jéssica - Contaria que o texto se trata de Física quântica de uma maneira que podemos entender, mais simplificado, o texto nos mostra uma visão mais ampla de como se aprende mais facilmente a física, utilizando outros métodos não somente as expressões algébricas e fórmulas complicadas. O nosso cotidiano.

A utilização de diferentes estratégias de ensino, em vias de possibilitar a produção de novos sentidos, porém, não garante que as noções científicas sejam apreendidas no sentido estrito em que são consideradas corretas dentro de seu corpo de conhecimentos. É o que podemos observar em respostas como a seguinte, da aluna Ester, em que possíveis equívocos e limitações na compreensão em como difere o comportamento físico para corpos em diferentes escalas de grandeza, podem ser mais bem explorados e aprofundados com a mediação do professor. A presença implícita da noção de escala, ainda que por meio das referências ao micro e macroscópico, para uma compreensão das particularidades da FQ, tanto em respostas mais genéricas quanto em explicitação de dúvidas e dificuldades, foi recorrente em alguns alunos.

Ester - Contaria que o texto se trata sobre quão diferente são os corpos microscópicos, como átomos e moléculas se comporta de maneira bastante diferente dos objetos macroscópicos de vida cotidiana. Esses são os princípios básicos da física quântica.

Reproduzimos a seguir as respostas às três primeiras questões de outros quatro estudantes, destacando alguns aspectos que nos levaram a buscar a compreensão de como produziram tais sentidos nas atividades de leitura como um todo. Lembramos que, na primeira questão, pedimos aos estudantes que contassem a um amigo sobre o que haviam lido no texto de Ferreira (2003), na segunda, perguntamos se haviam achado o texto de Planck (2012) interessante e, na terceira, solicitamos que apontassem suas dificuldades na leitura desse texto. 
João

$1^{\mathrm{a}} \mathrm{P}$ - Contaria sobre a minha dúvida sobre a barra de ferro que muda de cor quando é aquecida;

$2^{\mathrm{a}} \mathrm{P}-$ Sim, gostaria de conhecer mais sobre os átomos e ondas;

$3^{\mathrm{a}} \mathrm{P}$ - Tive dificuldades em algumas teorias, como por exemplo a teoria dos quanta.

Marisa

$1^{\mathrm{a}} \mathrm{P}$ - O texto se trata de fisica Quântica, mas não a que estamos acostumados, mas sim algo que possamos entender mais facil;

$2^{\mathrm{a}} \mathrm{P}$ - Achei muito bom, gostaria de saber mais sobre raios gamas e cores;

$3^{\mathrm{a}} \mathrm{P}$ - Dificuldade de entender a escala de grandeza.

Camila

$1^{a} \mathrm{P}$ - Sobre a física quântica, de uma maneira diferente aplicada no dia-a-dia e bem abrangente; de uma outra visão em relação à física e de quando e como surgiu ela;

$2^{\mathrm{a}} \mathrm{P}$ - Sim, algumas ideias do texto não foi estudada em sala de aula e foi algo diferente para se estudar do que já estávamos acostumados;

$3^{\mathrm{a}} \mathrm{P}$ - Algumas situações complicadas de entender em certos exemplos relacionadas à 'quant'.

Larissa

$1^{\mathrm{a}} \mathrm{P}$ - Física quântica é fácil de entender, podemos concluir que é a física das pequenas coisas, que compõem as coisas grandes;

$2^{\mathrm{a}} \mathrm{P}$ - Sim, pois sempre rotulei a física com "chata". Agora com as leituras dos textos pude me interessar mais sobre o assunto;

$3^{\mathrm{a}} \mathrm{P}$ - Fala-se numa linguagem de físicos que se não soubermos sobre física, fica um pouco vazio confuso.

Nas respostas de nenhum desses estudantes, pudemos visualizar uma cópia explicita de trechos dos textos, ou seja, os alunos não se limitaram a responder com uma repetição empírica de trechos em específico. Porém, muitas foram as referências a alguns termos do texto que remetem à física, em sua maioria para explicitar suas dúvidas, ou então evidenciar sobre o que gostariam de saber mais, como João e Marisa responderam. O estudante, inclusive, faz menção a elementos do quadro mais denso em conteúdo que finaliza o primeiro texto, relativo ao problema de investigação de Planck e outros conceitos físicos, quando se refere à barra de ferro que muda de cor, átomos e ondas. Juntamente com os conceitos a que Marisa se refere, as dificuldades que esses estudantes relatam explicitamente na terceira questão mostram que, mesmo com pequenas repetições de termos, houve em suas leituras grande atenção dada ao conteúdo da física.

Por outro lado, podemos considerar as respostas das estudantes Camila e Larissa à primeira questão, como repetições formais que tendem para histórica, se atentarmos para o fato de que, em suas formulações, estão incluídas referências que vão além dos conteúdos sobre física que os textos abordam. Camila insere uma noção de percurso ("quando e como") para se referir à FQ desde sua origem, após também fazer uma menção implícita ao cotidiano, enquanto Larissa se limita a resumir o ponto de comparação presente na introdução do primeiro texto. 
Porém, a ausência de um movimento para repetições históricas e formais de trechos significativos do texto em suas respostas seguintes não decorre da inexistência de interpretações pautadas em elementos nele presentes. Pelo contrário, Larissa apresenta sua dificuldade na resposta à terceira questão tratando justamente da "linguagem de físicos" como um elemento que impossibilita aprofundar sua compreensão. Produzida na chamada linguagem comum, a interlocução presumida por Planck, ao escrever diretamente a seus pares neste texto original que usamos na atividade de leitura, mostrou-se, para Larissa, de difícil interpretação, no que se refere à física nele tratada, como apontou a própria estudante.

Por fim, dentre as respostas à primeira questão de dois estudantes que não responderam todas as perguntas do questionário, limitando nossa investigação acerca de uma possível compreensão dos sentidos por eles produzidos, transcrevemos duas, pelas características pontuais que julgamos relevantes. A primeira, de Flávio, pela busca de uma explicação na qual pode ser subentendida a noção de escala envolvida. Sua formulação de sentido, apesar do equívoco com relação aos referentes na analogia apresentada, ao comparar uma ervilha com o átomo, e o estado de São Paulo com uma molécula, evidencia a necessidade de a aula não se restringir à leitura individual pelos alunos, mas também de se ter uma discussão para que esses sentidos possam ser debatidos. Já na segunda, de Millena, que foi a resposta mais longa à primeira questão, podemos notar sua tentativa de construir uma síntese do que havia lido e ainda a necessidade da discussão posterior. Ao ter acesso a um texto sobre física numa linguagem considerada comum, a estudante admite que existe o que não pode ser colocado numa fórmula e que, mesmo dentre os termos comuns que escolhe, pode haver alguma motivação ligada ao conteúdo científico a que quer se referir.

Flávio - Que se trata comparações feitas por cientistas entre coisas de tamanho extremo/ minisculo à coisas do cotidiano bumano (uma ervilha é um átomo, e a molécula seria o estado de SP);

Millena - Tudo que é grande é composto tudo muito pequeno. Não basta saber só fórmulas, se não tiver noção da teoria das formas como possamos 'ignorar' de certa forma a parte da teoria escrita e possamos a nos adaptar ao modo de formula. Há comparações de grandeza de um átomo, que não seria necessariamente não há como colocar na fórmula. Para o físico a teoria do átomo e a ideia de grandeza de um átomo ou o comportamento, o autor do texto trata como bizarro, talvez.porque na época o assunto chegou a chocar e a chege com que algumas teorias, fossem reformuladas, talvez isso é o que explicaria o por què do termo adotado pelo autor.

\section{Considerações finais}

Primeiramente, cabe aqui uma referência aos comentários de alguns estudantes que se manifestaram sobre a facilidade de compreender o que foi lido, que, de certa forma, podem estar associados a um imaginário sobre a FQ, já que o primeiro contato deles com esse conteúdo foi de uma forma com a qual estavam pouco acostumados: textos de cientistas, em linguagem comum. Certamente, como pudemos ver a partir da maioria das respostas às duas últimas perguntas do questionário, a abordagem de conteúdos da física por meio da leitura aproximou 
os estudantes de assuntos científicos com uma linguagem que, muitas vezes, é mais acessível do que a formalização matemática excessiva que se encontra nos conteúdos curriculares da disciplina escolar. A presença de elementos que fazem referência a procedimentos da ciência também contribui para deixar o texto mais narrativo, o que pode ter ajudado para despertar o interesse dos alunos.

É interessante notar que Maria associa aulas com fórmulas e contas a pouco conteúdo, uma vez que a leitura lhe possibilitou formular sentidos sobre ciência, diferentes daqueles presentes no tratamento matemático associado a definições pontuais e fechadas em si mesmas. Para os físicos que produzem essa ciência, as fórmulas são essenciais e talvez alguns acreditem que elas, em atividades de realização de exercícios, são o suficiente em qualquer nível de ensino. Entretanto, no ensino de física também é extremamente importante considerar como serão abordados os conteúdos em sala de aula.

A situação mais informal no desenvolvimento dessas atividades de leitura do que as usuais escolares, principalmente no que se refere à ausência de avaliação formal como ocorre na escola, certamente contribuiu para que não houvesse muitas respostas com repetições empíricas. As condições em que atividades de leitura como essas são realizadas se diferenciam substancialmente de situações formais. Entretanto, quando não assumimos uma posição de professor e propomos leituras em aula com questões abertas

[...] não deixamos de ter em conta a relevância das informações que o texto lido pode veicular. Mas queremos mais, queremos que as leituras propostas propiciem aos estudantes a oportunidade de refletirem sobre procedimentos de obtenção das informações que o texto veicula. E, também queremos que a leitura seja ensejo para que estudantes formulem suas próprias opiniões sobre o que leram e sobre o interdiscurso que a leitura pode produzir. (ALMEIDA; SOUZA; SILVA, 2006, p. 74).

O início da aula com uma leitura e uma questão bastante aberta para ser respondida pelos estudantes, seguida de uma discussão com caráter dialógico, permitiu um entrosamento entre o professor/pesquisador e os estudantes bastante diferenciado daquele da maioria das aulas quando são essencialmente expositivas. A utilização de textos de divulgação científica contribuiu nesse sentido, uma vez que, tratado como um importante recurso didático na educação em ciências, fundamenta a relação de seu discurso com os conhecimentos associados ao conhecimento científico em si e cria possibilidades para que tais textos funcionem como mediadores desses conhecimentos em situações de ensino (ALMEIDA, 2010). A utilização de alguns destes textos no ensino de física é de grande valor para os sentidos produzidos pelos alunos em seus esforços de compreensão na linguagem comum, assim como na interpretação dos conteúdos físicos envolvidos. Além de contribuir para que os estudantes se sintam mais seguros para exporem suas dúvidas, como foi o caso em outro estudo que realizamos em sala de aula no primeiro ano do nível médio de uma escola pública (PAGLIARINI; ALMEIDA, 2015).

O fato de as respostas terem sido bastante curtas pode ser em razão do tempo disponível, mas também precisamos ter em conta que escrever algo diferente de fórmulas e contas não é usual em aulas de física. Outro fator relevante, apontado por Almeida e Queiroz (1997, p. 67), é que a leitura de textos com termos desconhecidos pode criar dificuldades aos alunos, “[...] mas não impede que eles se manifestem motivados pelo texto, se a leitura for organizada 
como uma atividade que lhes pareça significativa. [...] Talvez seja possível falar dessa leitura como mediação para estabelecer uma nova relação com o conhecimento".

\section{Agradecimentos}

Os autores agradecem o apoio da Coordenação de Aperfeiçoamento de Pessoal de Nível Superior (CAPES) e do Conselho Nacional de Desenvolvimento Científico e Tecnológico (CNPq).

\section{Referências}

ALMEIDA, M. J. P. M. Discursos da ciência e da escola: ideologia e leituras possíveis. Campinas: Mercado de Letras, 2004.

- O texto de divulgação científica como recurso didático na mediação do discurso escolar relativo à ciência. In: PINTO, G. A. (Org.). Divulgação científica e práticas educativas. Curitiba: Editora CRV, 2010. p. 11-24.

ALMEIDA, M. J. P. M.; SOUZA, S. C.; SILVA, H. C. Perguntas, respostas e comentários dos estudantes como estratégia na produção de sentidos em sala de aula. In: NARDI, R.; ALMEIDA, M. J. P. M. (Org.). Analogias, leituras e modelos no ensino da ciência: a sala de aula em estudo. São Paulo: Escrituras, 2006. p. 61-74.

ALMEIDA, M. J. P. M.; QUEIROZ, E. C. L. Divulgação científica e conhecimento escolar: um ensaio com adultos. Cadernos CEDES, Campinas, n. 41, p. 62-68, 1997.

BRASIL. Ministério da Educação. Parâmetros curriculares nacionais - ensino médio. Brasília, 1999.

BROCKINGTON, G.; PIETROCOLA, M. O ensino de física moderna na escola média: os modelos e o realismo científico na sala de aula. In: ENCONTRO NACIONAL DE PESQUISA EM EDUCAÇÃO EM CIÊNCIAS, 5., 2005, Bauru. Anais... Bauru: ABRAPEC, 2005. 1 CD-ROM.

FERREIRA, L. A. Física quântica: o estranho comportamento do mundo microscópico. In: NATALE, A. A.; VIEIRA, C. L. (Org.). O universo sem mistério: uma visão descomplicada da física contemporânea: do big bang às partículas. Rio de Janeiro: Vieira \& Lent, 2003. p. 153-179.

GRECA, I. M.; MOREIRA, M. A. Uma revisão da literatura sobre estudos relativos ao ensino da mecânica quântica introdutória. Investigações em Ensino de Ciências, Porto Alegre, v. 6, n. 1, p. 29-56, 2001. Disponível em: < http://www.if.ufrgs.br/ienci/artigos/ Artigo_ID179/v6_n1_a2001.pdf>. Acesso em: 15 fev. 2016. 
GUERRA, A.; BRAGA, M.; REIS, J. C. Teoria da relatividade restrita e geral no programa de mecânica do ensino médio: uma possível abordagem. Revista Brasileira de Ensino de Física, São Paulo, v. 29, n. 4, p. 575-583, 2007. Disponível em: < http://dx.doi.org/10.1590/ S0102-47442007000400016>. Acesso em: 15 fev. 2016.

KARAM, R. A. S.; CRUZ, S. M. S. C.; COIMBRA, D. Relatividades no ensino médio: o debate em sala de aula. Revista Brasileira de Ensino de Física, São Paulo, v. 29, n. 1, p. 105-114, 2007. Disponível em: <http://dx.doi.org/10.1590/S1806-11172007000100017>. Acesso em: 15 fev. 2016.

LOBATO, T.; GRECA, I. M. Análise da inserção de conteúdos de teoria quântica nos currículos de física do ensino médio. Ciência \& Educação, Bauru, v. 11, n. 1, p. 119-132, 2005. Disponível em: <http://dx.doi.org/10.1590/S1516-73132005000100010>. Acesso em: 15 fev. 2016.

MARANDINO, M. A prática de ensino nas licenciaturas e a pesquisa em ensino de ciências: questões atuais. Caderno Brasileiro de Ensino de Física, Florianópolis, v. 20, n. 2, p. 168-193, 2003. Disponível em: <https://periodicos.ufsc.br/index.php/fisica/article/ view/6544>. Acesso em: 15 fev. 2016.

NARDI, R. (Org.). Questões atuais no ensino de ciências. São Paulo: Escrituras, 1998. (Coleção Educação para a ciência).

ORLANDI, E. P. Análise de discurso: princípios e procedimentos. 10. ed. Campinas: Pontes, 2012a.

Interpretação: autoria, leitura e efeitos do trabalho simbólico. 6. ed. Campinas: Pontes, 2012b.

. Para quem é o discurso pedagógico? In: ORLANDI, E. P. A linguagem e seu funcionamento: as formas do discurso. Campinas: Pontes, 1996. p. 25-38.

. Paráfrase e polissemia: a fluidez nos limites do simbólico. RUA: Revista do

Laboratório de Estudos Urbanos do Núcleo de Desenvolvimento da Criatividade, Campinas, v. 4, p. 9-19, 1998.

OSTERMANN, F.; MOREIRA, M. A. Atualização do currículo de física na escola de nível médio: um estudo dessa problemática na perspectiva de uma experiência em sala de aula e da formação inicial de professores. Caderno Brasileiro de Ensino de Física, Florianópolis, v. 18, n. 2, p. 135-151, 2001. Disponível em: < https://periodicos.ufsc.br/index.php/fisica/ article/view/6676>. Acesso em: 16 fev. 2016.

. Uma revisão bibliográfica sobre a área de pesquisa "física moderna e contemporânea no ensino médio". Investigações em Ensino de Ciências, Porto Alegre, v. 5, n. 1, p. 23-48, 2000. Disponível em: <http://www.if.ufrgs.br/ienci/artigos/Artigo_ ID57/v5_n1_a2000.pdf>. Acesso em: 16 fev. 2016. 
PAGLIARINI, C. R.; ALMEIDA, M. J. P. M. Física quântica numa leitura de divulgação científica no início do ensino médio: manifestações dos estudantes. In: GIORDAN, M.; CUNHA, M. B. (Org.). Divulgação científica na sala de aula: perspectivas e possibilidades. Ijuí: Editora Unijuí, 2015. p. 249-284.

PEREIRA, A. P.; OSTERMANN, F. Sobre o ensino de física moderna e contemporânea: uma revisão da produção acadêmica recente. Investigações em Ensino de Ciências, Porto Alegre, v. 14, n. 3, p. 393-420, 2009. Disponível em: <http://www.if.ufrgs.br/ienci/artigos/ Artigo_ID224/v14_n3_a2009.pdf>. Acesso em: 16 fev. 2016.

PIETROCOLA, M. Ensino de física: conteúdo, metodologia e epistemologia numa concepção integradora. Florianópolis: Editora da UFSC, 2001.

PINTO, A. C.; ZANETIC, J. É possível levar a física quântica para o ensino médio? Caderno Catarinense de Ensino de Física, Florianópolis, v. 16, n. 1, p. 7-34, 1999. Disponível em: <https://periodicos.ufsc.br/index.php/fisica/article/view/6873/6333>. Acesso em: 16 fev. 2016.

PLANCK, M. Novas vias de acesso ao conhecimento da física. In: Autobiografia científica e outros ensaios. Rio de Janeiro: Contraponto, 2012. p. 89-99.

SÃO PAULO (Estado). Secretaria de Educação. Currículo do Estado de São Paulo: ciências da natureza e suas tecnologias. São Paulo, 2012. Disponível em: <http://www. educacao.sp.gov.br/a2sitebox/arquivos/documentos/780.pdf>. Acesso em: 16 fev. 2016.

SILVA, A. C.; ALMEIDA, M. J. P. M. Física quântica no ensino médio: o que dizem as pesquisas. Caderno Brasileiro de Ensino de Física, Florianópolis, v. 28, n. 3, p. 624-653, 2011. Disponível em: <http://dx.doi.org/10.5007/2175-7941.2011v28n3p624>. Acesso em: 16 fev. 2016.

SILVA, C. C. Estudos de história e filosofia das ciências: subsídios para aplicação no ensino. São Paulo: Livraria da Física, 2006.

TERRAZZAN, E. A. A inserção da física moderna e contemporânea no ensino de física na escola de $2^{\circ}$ grau. Caderno Catarinense de Ensino de Física, Florianópolis, v. 9, n. 3, p. 209-214, 1992. Disponível em: < https://periodicos.ufsc.br/index.php/fisica/article/ view/7392>. Acesso em: 16 fev. 2016.

WOLFF, J. F. S.; MORS, P. M. Relatividade no ensino médio: uma experiência com motivação na história. Experiências em Ensino de Ciências, Cuiabá, v. 1, n.1, p. 14-22, 2006. Disponível em: < http://if.ufmt.br/eenci/artigos/Artigo_ID15/pdf/2006_1_1_15. pdf $>$. Acesso em: 16 fev. 2016.

Artigo recebido em 28/11/2014. Aceito em 21/12/2015.

Endereço para contato: Universidade Estadual de Campinas, Faculdade de Educação, Av. Bertrand Russell 801, Prédio Principal, Térreo, Bloco D, sala 06 (gepCE), Cidade Universitária, Barão Geraldo, CEP: 13083-865, Campinas, SP, Brasil. 